\title{
ACUTE LUNG INJURY IN A WORKER AFTER INHALATION OF ETHYLENE PHOSPHORODIFLUORIDITE
}

\section{SEUNG WON RA ${ }^{1}$, JIMI OH${ }^{2}$, HOCHANG KIM ${ }^{2}$, WOON JUNG KWON ${ }^{3}$, and YANGHO KIM ${ }^{4}$}

University of Ulsan College of Medicine, Ulsan, Republic of Korea

Ulsan University Hospital

${ }^{1}$ Department of Respiratory and Critical Care Medicine

${ }^{2}$ Department of Anesthesiology and Pain Medicine

${ }^{3}$ Department of Diagnostic Radiology

${ }^{4}$ Department of Occupational and Environmental Medicine

\begin{abstract}
Ethylene phosphorodifluoridite $\left(\mathrm{C}_{2} \mathrm{H}_{4} \mathrm{~F}_{4} \mathrm{O}_{2} \mathrm{P}_{2}\right)$ (CAS No. 3965-00-2) is a colorless corrosive fuming liquid that is used as a stabilizer in the electrolyte of rechargeable batteries. There are no previous reports of toxic effects following exposure to this compound. A 28-year-old male complained of respiratory distress after accidental inhalation of ethylene phosphorodifluoridite for $30 \mathrm{~min}$. The patient developed acute lung injury with noncardiogenic pulmonary edema and was treated with supportive management. The patient fully recovered and was discharged after 7 days without any significant sequelae. The patient's symptoms were attributed to non-cardiogenic pulmonary edema caused by ethylene phosphorodifluoridite exposure. The case study showed that ethylene phosphorodifluoridite should be added to the list of chemicals that can cause acute lung injury. Int J Occup Med Environ Health. 2022;35(3):361-6
\end{abstract}

Key words:

exposure, inhalation, acute, lung injury, pulmonary edema, ethylene phosphorodifluoridite

\section{BACKGROUND}

Acute exposure to a high concentration of a toxic gas can cause inhalation injury to the respiratory tract [1]. For a given toxic gas, the concentration, water solubility, and duration of exposure determine the extent of respiratory damage and other clinical effects [2]. Depending on the type and the amount of chemical inhaled, a patient may experience symptoms that range from minor respiratory tract discomfort to injuries of the lung parenchyma cells that lead to pneumonitis, pulmonary edema, acute respiratory distress syndrome, and even death. Water-soluble gases dissolve in the upper airway and immediately cause mucous membrane irritation, so an exposed individual can act quickly to avoid additional exposure. In contrast, gasses with less water solubility may not dissolve until they are well into the respiratory tract, often the lower airways, where they can cause severe bronchiolitis [3]. A respiratory system exposed to toxic chemicals may also act as a systemic toxin delivery system.

Received: March 23, 2021. Accepted: November 17, 2021.

Corresponding author: Yangho Kim, University of Ulsan College of Medicine, Ulsan University Hospital, Department of Occupational and Environmental Medicine, 877 Bangeojinsunhwan-doro, Dong-gu, Ulsan, 44033, Republic of Korea (e-mail: yanghokm@ulsan.ac.kr). 
Ethylene phosphorodifluoridite (1,2-bis-difluorophosphanyloxy-ethane) $\left(\mathrm{C}_{2} \mathrm{H}_{4} \mathrm{~F}_{4} \mathrm{O}_{2} \mathrm{P}_{2}\right)$ (CAS No. 3965-00-2) is a colorless, corrosive fuming liquid that is water-soluble ( $3.9 \mathrm{~g} / 100 \mathrm{ml}$ water), and adopted as an electrolyte stabilizer in rechargeable batteries. There are no previous reports of the toxic effects of ethylene phosphorodifluoridite inhalation. In this report, we describe a patient who developed acute lung injury after accidental inhalation of ethylene phosphorodifluoridite.

\section{CASE REPORT}

A 28-year-old male worker who was previously healthy and a non-smoker, was transported to the emergency center of a local general hospital approximately $1 \mathrm{~h}$ after accidental exposure to ethylene phosphorodifluoridite (1,2-bis-difluorophosphanyloxy-ethane), a stabilizer used in the electrolyte of rechargeable batteries, for $30 \mathrm{~min}$.

\section{Exposure scenario}

He worked in a process in a chemical factory where a reactor produced ethylene phosphorodifluoridite. The reaction in the reactor was as follows: 3 (1,2-bis-dichlorophosphinoyloxy-ethane) $+4 \mathrm{SbF}_{3} \rightarrow 3$ (1,2-bis-difluorophosphanyloxy-ethane; ethylene phosphorodifluoridite) $+4 \mathrm{SbCl}_{3}$. He was accidentally exposed to ethylene phosphorodifluoridite leaked from the reactor for approx. $30 \mathrm{~min}$ due to the mistake of valve operation by another worker in an operating room. He was working close to the reactor, and was most likely exposed to a high concentration of ethylene phosphorodifluoridite because this material, with a boiling point of $89.6^{\circ} \mathrm{C}$, was synthesized in the reactor at an operation temperature of $250^{\circ} \mathrm{C}$. After the accident, the safety manager confirmed that the leaked gas was ethylene phosphorodifluoridite. However, the quantitative exposure assessment of ethylene phosphorodifluoridite was not performed. He was wearing a half-face airpurifying respirator with cartridges providing protection against organic vapor.

\section{Clinical information}

The patient initially experienced dizziness, nausea, and general malaise, and then fainted. The other worker who was further away from the reactor, and was not exposed to ethylene phosphorodifluoridite found him collapsed on the floor. Approximately $1 \mathrm{~h}$ after the initial exposure, his vital signs were stable (blood pressure: 120/80 mm Hg, heart rate: $80 \mathrm{bpm}$, respiratory rate: 16 breaths/min, temperature: $37.0^{\circ} \mathrm{C}, \mathrm{O}_{2}$ saturation $\left(\mathrm{SpO}_{2}\right): 99 \%$ in room air). However, he gradually suffered from worsening dyspnea and an increased respiratory rate. An initial arterial blood gas analysis (ABGA) showed a pH of 7.42, a carbon dioxide pressure $\left(\mathrm{PaCO}_{2}\right)$ of $37 \mathrm{~mm} \mathrm{Hg}$, a $\mathrm{PaO}_{2}$ of $72 \mathrm{~mm} \mathrm{Hg}$, a bicarbonate $\left(\mathrm{HCO}^{3-}\right)$ level of $24.7 \mathrm{mmol} / \mathrm{l}$, and $93 \%$ oxygen saturation of arterial blood $\left(\mathrm{SaO}_{2}\right)$ with $3 \mathrm{l} / \mathrm{min}$ of oxygen administered via a nasal cannula. The alveolar-artery oxygen difference $\left(\mathrm{AaDO}_{2}\right)$ was calculated as $110 \mathrm{~mm} \mathrm{Hg}$, suggesting gas exchange problems. A reserve mask with $15 \mathrm{l} / \mathrm{min} \mathrm{O}_{2}$ was needed to keep his $\mathrm{SpO}_{2}$ in the normal range before transfer to Ulsan University Hospital, Ulsan, Republic of Korea.

Upon arrival at the emergency department of Ulsan University Hospital ( $3.5 \mathrm{~h}$ after exposure), the patient was still dyspneic and complained of chest tightness, although his vital signs were stable. During inhalation of $15 \mathrm{l} / \mathrm{min} \mathrm{O}_{2}$ via a reserve mask, $\mathrm{ABGA}$ indicated acute respiratory acidosis $\left(\mathrm{pH} \mathrm{7.35}, \mathrm{PaCO}_{2} 45 \mathrm{~mm} \mathrm{Hg}, \mathrm{PaO}_{2}\right.$ $159 \mathrm{~mm} \mathrm{Hg}, \mathrm{HCO}^{3-} 24.8 \mathrm{mmol} / \mathrm{l}$, lactate $3.5 \mathrm{mmol} / \mathrm{l}$, and $\mathrm{SaO}_{2}$ 99\%). The $\mathrm{AaDO}_{2}$ was greatly aggravated (493 mm Hg). The results of a physical examination were unremarkable except for a first-degree chemical burn limited to the right forearm. The laboratory findings showed elevated levels of D-dimer $(4.74 \mu \mathrm{g} / \mathrm{ml}$, reference range: $0.0-0.5 \mu \mathrm{g} / \mathrm{ml})$, lactate $(3.5 \mathrm{mmol} / \mathrm{l}$, reference range: $0.5-2.5 \mathrm{mmol} / \mathrm{l})$, procalcitonin (РCT) $(3.14 \mathrm{ng} / \mathrm{ml}$, reference range: $0.0-0.05 \mathrm{ng} / \mathrm{ml}$ ), and $\mathrm{LDH}$ (258 IU/l, reference range: 106-230 IU/l), but normal levels of carboxyhemoglobin, methemoglobin, and C-reactive pro- 
a)

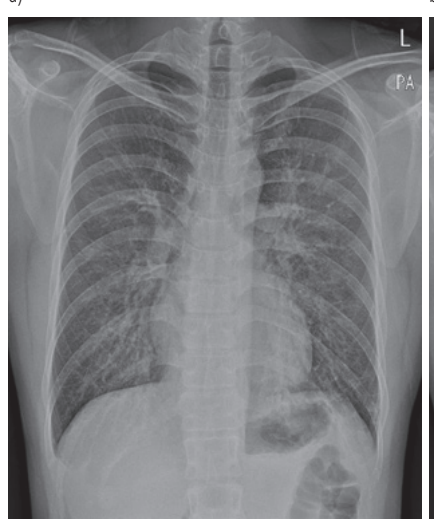

b)

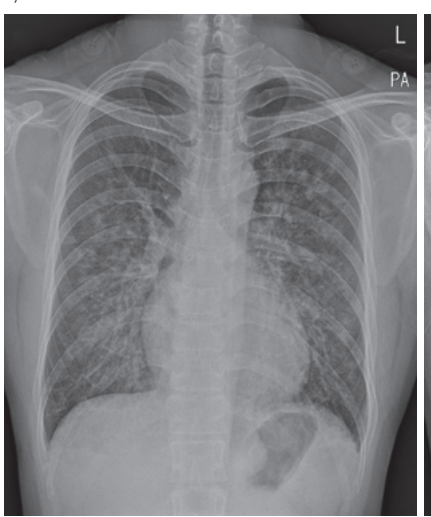

c)

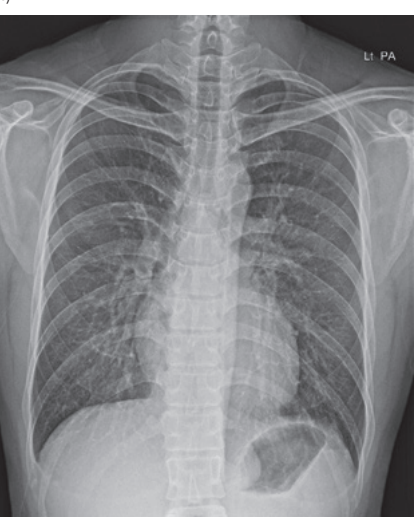

d)

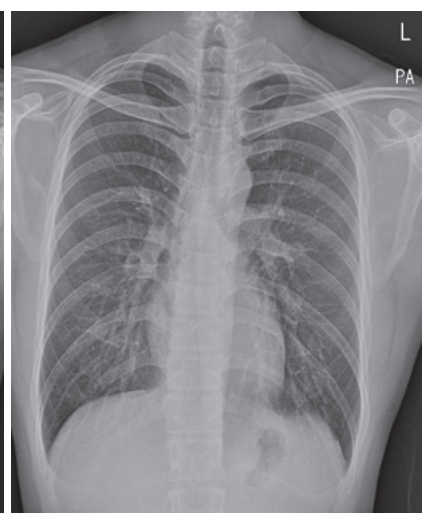

Figure 1. Chest $X$-rays, showing ill-defined pulmonary nodules and increased opacities in both lungs, with rapid resolution during follow-up: a) $4 \mathrm{~h}$ after exposure, b) hospital day 2, c) hospital day 4, d) hospital day 7, May 2020, Ulsan University Hospital, Ulsan, Republic of Korea

a)

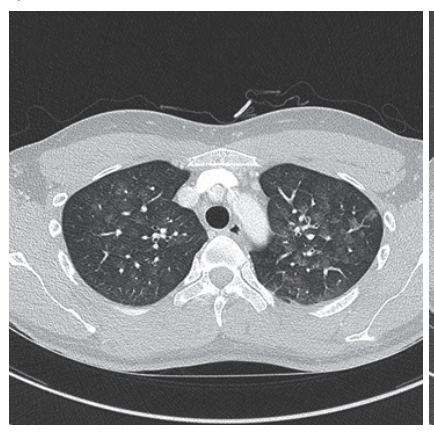

b)

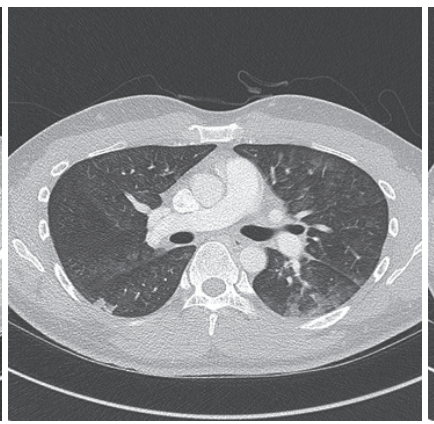

c)

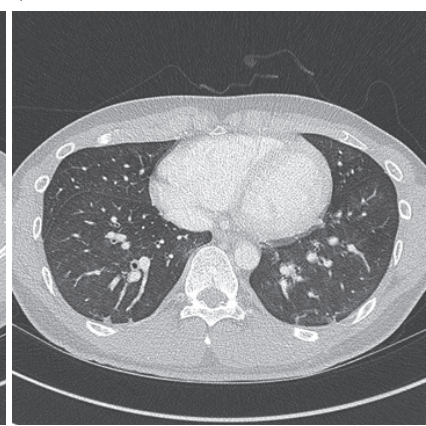

d)

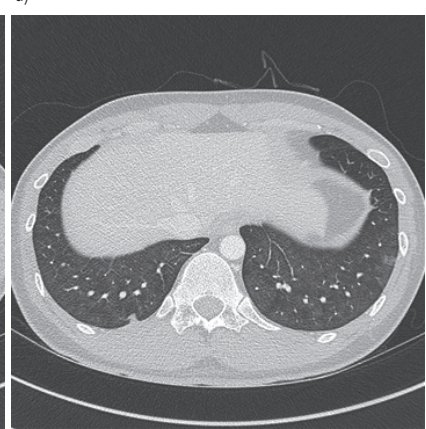

Figure 2. Chest computed tomography at $6 \mathrm{~h}$ after exposure, showing extensive centrilobular distributed ill-defined ground-glass opacities with smooth interlobular septal thickenings in the both lungs: a) aortic arch level, b) right main pulmonary artery level, c) heart base level, d) both lower lobe basal segment level (the smooth interlobular septal thickenings were more prominently distributed in the both lower lobes (c,d)), May 2020, Ulsan University Hospital, Ulsan, Republic of Korea

tein (CRP). There were no other serological or laboratory abnormalities (coagulation, electrolyte, blood chemistry, cardiac markers, and brain natriuretic peptide levels) except for mild hypocalcemia $(1.12 \mathrm{mmol} / \mathrm{l}$, reference range: $1.14-1.32 \mathrm{mmol} / \mathrm{l}$ ).

A chest X-ray showed ill-defined pulmonary nodules and increased opacities in both lungs (Figure 1a). A chest computed tomography (CT) showed extensive ill-defined ground-glass opacities (GGOs) with smooth interlobular septal thickenings in both lungs (Figure 2). The GGO lesions had a centrilobular distribution with subpleural sparing in both upper lobes, but the diffuse GGOs with interlobular septal thickenings in both lower lobes sug- gested more prominent features of pulmonary edema than the upper lobes (Figure 2). The subpleural consolidative nodules in both lower lobes in the chest CT could be interpreted as atelectasis. Two hours after arrival at the hospital, he was weaned from the reserve mask and a $6 \mathrm{l} / \mathrm{min}$ nasal cannula with a $\mathrm{SpO}_{2}$ of $98 \%$ was used.

The next day, his dyspnea and chest tightness worsened. During nasal inhalation of $3 \mathrm{l} / \mathrm{min}$ of oxygen, the results of an ABGA (pH 7.339, $\mathrm{PaCO}_{2} 46.6 \mathrm{~mm} \mathrm{Hg}, \mathrm{PaO}_{2}$ $73.8 \mathrm{~mm} \mathrm{Hg}, \mathrm{HCO}^{3-} 24.5 \mathrm{mmol} / \mathrm{l}$, lactate $2.32 \mathrm{mmol} / \mathrm{l}$, $\mathrm{SaO}_{2} 94 \%, \mathrm{AaDO}_{2} 76 \mathrm{~mm} \mathrm{Hg}$ ) suggested acute respiratory acidosis (Figure $1 \mathrm{~b}$ ). On day 3 , the patient continued to have mild dyspnea, but his hypoxemia and laboratory 
a)

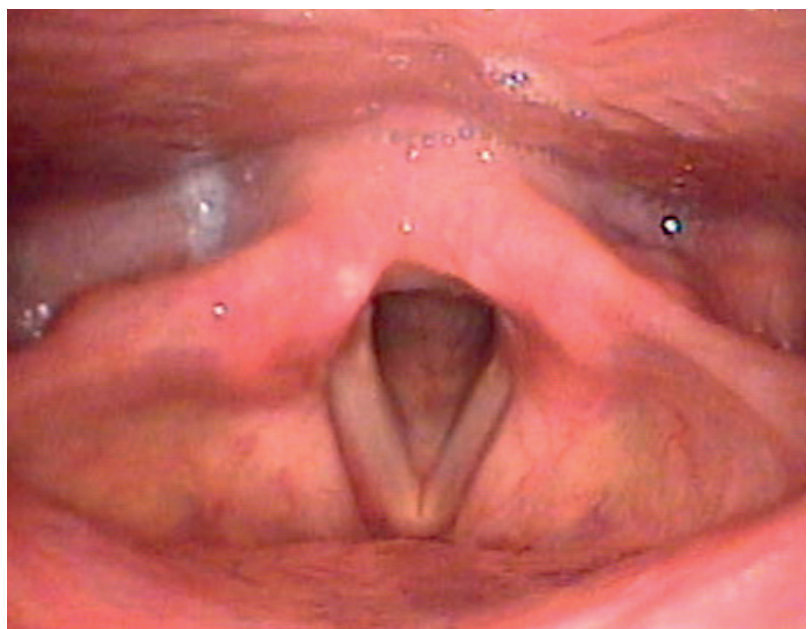

b)

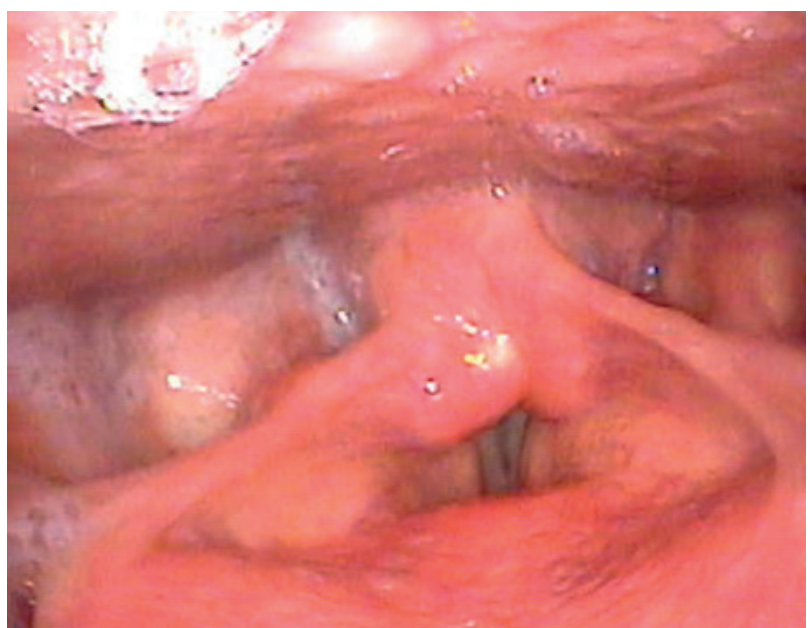

Figure 3. Fiberoptic laryngoscopy showing damage of the mucus membranes and mild edematous changes in the larynx: a) at normal inspiration, b) at phonation, May 2020, Ulsan University Hospital, Ulsan, Republic of Korea

findings showed marked improvement after oxygen inhalation and on day 4, the patient complained of a sore throat. An inhalation injury to the upper respiratory tract was suspected, and examination using a laryngoscope indicated damage of the mucus membranes and a mild edematous change of the larynx (Figure $1 \mathrm{c}$ and 3). On day 7, a chest X-ray and CT showed a complete resolution of the previous ill-defined GGOs and interlobular septal thickening (Figures 1d). His respiratory condition continued to improve gradually, and he was discharged after 8 days without the need for any medication. Thus, acute lung injury following the inhalation of ethylene phosphorodifluoridite was manifested as non-cardiogenic pulmonary edema. His daily activities soon returned to normal and he has experienced no respiratory problems. At the follow-up of 8 months after discharge, he did not complain of any respiratory problems. The patient provided permission for publication of his medical data.

\section{DISCUSSION}

Ethylene phosphorodifluoridite is a compound consisting of phosphorus and fluorine, making it highly toxic upon inhalation. There are previous case reports of acute lung injury following inhalation of phosphoric acid and of hydrogen fluoride, but no previously reported cases of exposure to ethylene phosphorodifluoridite in humans. This may explain why there are no occupational exposure limits or reports of toxicity of this chemical in Korea or other countries. Material safety data sheet provides toxicological information such as severe skin corrosion/irritation and serious eye damage/irritation in rabbits, and acute oral toxicity of $\mathrm{LD}_{50}$ in rat $=200 \mathrm{mg} / \mathrm{kg}$ (category 3 ) without information on inhalation or dermal toxicity. However, it does not provide any toxicological information on respiratory or skin sensitization, germ cell mutagenicity, carcinogenicity, reproductive toxicity, and specific target organ toxicity related to single or repeated exposure. Workplace exposure limits or any health effects in humans were not available. The case study showed that ethylene phosphorodifluoridite should be added to the list of chemicals that can cause acute lung injury. Inhalation of a wide range of toxic substances can lead to acute lung injury, and inhalation of high concentrations can cause acute inflammation resulting in damage to the respiratory system. Lung CT scans of patients who inhaled other highly soluble toxic gases tend to show 
extensive GGOs, but less soluble gases tend to show centrilobular lesions [4]. The authors hypothesized that the toxic effects of ethylene phosphorodifluoridite could have been due to phosphoric acid or hydrogen fluoride. Hence, authors managed the patient based on the toxic effects of both chemicals.

Previous studies reported that accidental inhalation of either substance can lead to acute lung injury, from mild symptoms to severe disease such as pulmonary edema, bronchopneumonia, acute respiratory distress syndrome [5-7]. In addition, one study reported that inhalation of phosphorus pentafluoride caused lung injury, including pulmonary edema [8].

The chest CT findings of the patient showed diffuse GGOs with interlobular septal thickening, but they resolved rapidly and there were no residual lung lesions 1 week later. The authors assume that the CT findings were attributable to non-cardiogenic permeability edema. Thus, lung injuries due to inhalation of phosphoric acid or hydrogen fluoride are similar to those in the patient. The unique CT findings of the patient were similar to non-cardiogenic pulmonary edema induced by acute exposure to nitrogen dioxide [4]. The authors attributed the patient's symptoms to non-cardiogenic pulmonary edema caused by ethylene phosphorodifluoridite exposure, by reasoning that:

- the patient's clinical course and radiologic findings suggested pulmonary edema,

- the event happened following exposure to ethylene phosphorodifluoridite,

- the other possible causes of pulmonary edema were excluded.

The patient had no specific laboratory results suggestive of severe hydrogen fluoride intoxication, which is characterized by progressive inflammation and a local tissue reaction, and binding to intracellular calcium and magnesium, leading to systemic electrolyte disturbance. The ability of hydrogen fluoride to cause tissue necrosis and hypocalcemia is due to the toxicity of the highly electronegative fluoride ion rather than the hydrogen ion. Diluted solutions of hydrogen fluoride $(<20 \%)$ can lead to delayed and severe injury [9], but concentrated solutions $(>40 \%)$ can lead to rapid and pronounced injury, such as immediate pain and skin damage [9]. The patient had a first-degree chemical burn limited to the right forearm and mild hypocalcemia soon after exposure to ethylene phosphorodifluoridite. Even though the authors did not administer prophylactic calcium gluconate, his calcium level soon returned to normal and the burn did not progress.

The solubility and physicochemical properties of ethylene phosphorodifluoridite were different from those of hydrogen fluoride. Thus, the present case can be differentiated from hydrogen fluoride intoxication. In addition, the authors noted an early and transient elevation of PCT, and this marker seemed proportional to the severity of tissue damage. Similarly, previous studies reported transient elevation of PCT in patients with burn-related severe inflammation without evidence of infection and in patients with uncomplicated trauma $[10,11]$.

The patient also had no bacterial infections or other sequelae of acute lung injury. This finding is consistent with the initial blood test, which showed an elevated PCT but a normal CRP. The pathogenesis of inhalation injury from ethylene phosphorodifluoridite is not clear. However, the authors suggest that exposure to this compound leads to reversible acute lung injury with non-cardiogenic pulmonary edema, and that this injury resolves spontaneously without serious complications. The standard treatment for acute lung injury is typically supportive care. In this patient, supportive care with oxygen inhalation and symptomatic treatment, including antitussives and pain relievers, were provided depending on the symptoms. In addition, identification of the inhaled agent and of the duration and intensity of exposure are also important in the treatment.

This case report has several toxicological implications. First, many new industrial chemicals with unknown 
toxicity, such as ethylene phosphorodifluoridite, are produced and used at workplaces due to the rapid development of the materials industry. Caution should be exercised to prevent acute lung injury due to inhalation of unknown chemical compounds that include phosphorus and fluorine. Second, it is important to consider that inhaled toxic chemicals, such as ethylene phosphorodifluoridite, may lead to significant pulmonary disease even if the initial symptoms are mild. Therefore, patients should be monitored closely regardless of initial symptoms. A limitation of this case report is that the authors were unable to estimate the amount of ethylene phosphorodifluoridite that the patient inhaled.

\section{CONCLUSIONS}

This case highlights the importance of safety when using ethylene phosphorodifluoridite, which was recently introduced for use in rechargeable batteries due to the rapid development of the materials industry. Inhaled ethylene phosphorodifluoridite may cause acute lung injury with non-cardiogenic pulmonary edema. Supportive management with oxygen led to complete clinical recovery of the patient described here. However, further studies should be performed to confirm the relationship between inhalation of ethylene phosphorodifluoridite and noncardiogenic pulmonary edema.

\section{REFERENCES}

1. Kales SN, Christiani DC. Acute chemical emergencies. N Engl J Med 2004;350(8):800-8. https://doi.org/10.1056/NEJMra 030370 .
2. McKay CA, Jr. Toxin-induced respiratory distress. Emerg Med Clin North Am. 2014;32(1):127-47. https://doi.org/10. 1016/j.emc.2013.09.003.

3. Jegal Y, Kim Y. Industrial chemicals and acute lung injury with a focus on exposure scenarios. Curr Respir Med Rev. 2016;12(1):44-55.

4. Akira M, Suganuma N. Acute and subacute chemical-induced lung injuries: HRCT findings. Eur J Radiol. 2014;83(8):14619. https://doi.org/10.1016/j.ejrad.2014.04.024.

5. Gorguner M, Akgun M. Acute inhalation injury. Eurasian J Med. 2010;42(1):28-35. https://doi.org/10.5152/eajm.2010.09.

6. Albert RK, Spiro SG, Jett JR. Clinical respiratory medicine: Elsevier Health Sciences; 2008.

7. Purva SB, More KD. Acute Lung Injury after Exposure to Fumes of Pickling Paste in a Fabrication Worker. Indian J Occup Environ Med. 2018;22(1):54-6. https://doi.org/10. 4103/ijoem.IJOEM_162_17.

8. Windholz M, editor. The Merck Index, 10th ed. Rahway: Merck \& Co; 1983.

9. Tylenda CA. Toxicological profile for fluorides, hydrogen fluoride, and fluorine: Agency for Toxic Substances and Disease Registry; 2003.

10. Mimoz O, Benoist JF, Edouard AR, Assicot M, Bohuon C, Samii K. Procalcitonin and C-reactive protein during the early posttraumatic systemic inflammatory response syndrome. Intensive Care Med. 1998;24(2):185-8. https://doi. org/10.1007/s001340050543.

11. De Bastiani G, Mosconi F, Spagnol G, Nicolato A, Ferrari S, Aprili F. High calcitonin levels in unconscious polytrauma patients. J Bone Joint Surg Br. 1992;74(1):101-4. https://doi. org/10.1302/0301-620X.74B1.1732234.

This work is available in Open Access model and licensed under a Creative Commons Attribution-NonCommercial 3.0 Poland License - http://creativecommons.org/ licenses/by-nc/3.0/pl/deed.en. 